\title{
Nexo entre água, energia e alimento no contexto das mudanças do clima: o caso do Nordeste brasileiro.
}

1. Este artigo foi desenvolvido a partir de pesquisa financiada pelo CNPq e pela FAPEMIG

2. Doutora em Sociologia e Política, DCP/UFMG. Professora do Departamento de Relações Internacionais da PUC Minas. Belo Horizonte, Brasil. ORCID: 0000-0001-5241-5644

3. Mestre em Relações Internacionais, PPGRI/PUC Minas. Pesquisador na PUC Minas, Belo Horizonte/Brasil, com experiência em cooperação internacional e meio ambiente. ORCID: 000-00017039-8980
Nexus water, energy, and food in the context of climate change: the case of Northeast Brazil

\section{Nexo entre agua, energía y alimentos en el contexto del cambio climático: el caso del noreste de Brasil}

\author{
Matilde de Souza ${ }^{2}$ \\ Bernardo Hoffman Versieux ${ }^{3}$
}

DOI: 10.5752/P.2317-773X.2021v9.n1.p112

Recebido em: 21 de abril de 2020

Aceito em: 13 de setembro de 2020

\begin{abstract}
ResUMO
Este artigo analisa ações do governo brasileiro para a segurança hídrica, energética e alimentar para discutir se expressam o nexo entre água, energia e alimento, WEF, considerando as políticas que as fundamentam. São observados desafios de adaptação impostos pelas mudanças do clima, sendo a água o elemento chave. Usando técnicas de análise documental, são analisados o Plano Nacional de Mudanças Climáticas e relatórios de ações governamentais na Região Nordeste. A pergunta da pesquisa é se programas para implementação de políticas voltadas para os eixos do nexo WEF expressam inter-relações entre eles. A hipótese é que os programas deixam a desejar quanto à governança ambiental a partir da perspectiva do nexo WEF porque as políticas se desenvolveram a partir de abordagem setorial e os programas de implantação não a debelaram, observando-se lacunas que, caso superadas, poderiam contribuir para que se avance na direção da governança integrada e sistêmica.
\end{abstract}

Palavras chave: Nexo WEF. Segurança Hídrica. Segurança Energética. Segurança Alimentar.

\footnotetext{
ABSTRACT

This article analyzes actions by the Brazilian government for water, energy, and food security to discuss whether the nexus between water, energy, and food, WEF, is expressed, considering the policies that underlie them. Adaptation challenges imposed by climate change are observed, with water being the key element. We analyze the National Climate Change Plan and government action reports in the Northeast Region using document analysis techniques. The research question is whether programs to implement policies aimed at the axes of the WEF nexus express interrelationships between them. The hypothesis is that
} 
the programs leave something to be desired regarding environmental governance from the perspective of the WEF nexus because policies were developed from a sectoral approach and the implementation programs did not overcome it, observing gaps that, if overcome, could contribute to moving towards integrated and systemic governance.

Keywords: WEF Nexus. Water Security. Energy Security. Food Security.

\section{RESUMEN}

Este artículo analiza las acciones del gobierno brasileño en materia de agua, energía y seguridad alimentaria para discutir si se expresa el nexo entre agua, energía y alimentos, WEF, considerando las políticas que las sustentan. Se observan los desafíos de adaptación impuestos por el cambio climático, siendo el agua el elemento clave. Mediante técnicas de análisis documental se analiza el Plan Nacional de Cambio Climático y los informes de acción del gobierno en la Región Nordeste. La pregunta de investigación es si los programas de implementación de políticas dirigidas a los ejes del nexo del WEF expresan interrelaciones entre ellos. La hipótesis es que los programas dejan algo que desear en materia de gobernanza ambiental desde la perspectiva del nexo del WEF porque las políticas se desarrollaron desde un enfoque sectorial y los programas de implementación no lo superaron, observándose brechas que de superarse podrían contribuir a avanzar hacia una gobernanza integrada y sistémica.

Palabras clave: Nexo WEF. Seguridad del Agua. Seguridad Energética. Seguridad Alimentaria.

Introdução

Este artigo analisa ações voltadas para a garantia da segurança hídrica, energética e alimentar, e discute se tais ações expressam o nexo entre água, energia e alimento, WEF, considerando as políticas que as fundamentam. Essa discussão toma as mudanças do clima como elemento impulsionador dos desafios para se atender às demandas por água, energia e alimentos, e assegurar à população acesso a esses recursos. Será analisado o caso da região Nordeste do Brasil, no período de 2003 a $2018^{4}$. Objetiva-se tratar os desafios de adaptação impostos pelas mudanças do clima, tendo a água como elemento chave no nexo WEF, por ser recurso insubstituível, importante para a geração de energia e por sua imprescindibilidade para a produção de alimentos em larga escala (IRUJO, 2017).

Pode-se identificar a concepção do nexo WEF desde o Relatório Brundtland. Alguns autores o localizam em contextos anteriores a 1972. Seu significado tem sido acionado porque possibilita vinculação dos seus elementos às mudanças do clima (MCs) (SIMPSON; JEWITT, 2019). O conceito ganhou maior impulso a partir da Conferência "The Water Energy and Food Security Nexus - Solutions for the Green Economy", realizada em Bonn, em 2011, por iniciativa do governo alemão em colaboração com o Fórum Econômico Mundial, a World Wildlife Fund e $o$ International Food Policy Research Institute. A proposta era contribuir para a Rio+20 no debate sobre os Objetivos do Desenvolvimento Sustentável (IISD, 2011). O conceito refere-se à conexão entre os riscos relativos à
4. A demarcação temporal foi definida em razão de alterações nas estruturas de gestão ambiental a partir de 2019. 
segurança hídrica, energética e alimentar, dados os desafios interpostos por uma combinação de fatores: ecossistemas degradados, crescente demanda por recursos, mudanças globais do clima, urbanização e globalização. Face a essa combinação, alto grau de insegurança pode ser gerado. A proposta geral do conceito é prover uma abordagem desses três elementos, visando sua melhor e mais articulada governança (HOFF, 2011).

Esse conceito tem sofrido críticas: pouco consenso quanto ao seu significado, ambiguidade, normatividade, arbitrariedade na seleção dos elementos, dentre outros aspectos. Inicialmente muito focado na segurança, ele foi ampliado para abordar conexões e interdependências, além da integração dos aspectos da gestão sustentável dos recursos. Apesar dessas críticas, vários autores o mobilizam, por é um conceito que permite tratar a gestão integrada dos recursos hídricos (GIRH) como eixo articulador e discutir aspectos da governança dos elementos do nexo WEF a partir da presença ou ausência dessas conexões (SIMPSON; JEWITT, 2019). É nesse sentido que o conceito é mobilizado neste artigo. A GIRH já supõe que esses recursos serão geridos de modo articulado a outras dimensões ambientais (SOUZA, 2003). Concebe-se que as estruturas de gestão devem estar articuladas e em comunicação, complementando e conectando políticas, planos e programas de implementação. Esses elementos orientam a análise do nexo WEF aqui realizada.

Esse esforço envolve a análise do Plano Nacional de Mudanças Climáticas e de registros de ações governamentais no Nordeste, por ser região mais vulnerável aos impactos das MCs. Considerando-se que o país possui políticas ambientais complexas (BENJAMIN et al., 2011), a pergunta que direciona este artigo é se programas de implantação dessas políticas expressam o nexo WEF. A hipótese é que os programas deixam a desejar quanto à governança ambiental pela perspectiva do nexo porque as políticas se desenvolveram a partir de abordagem setorial e os programas de implantação não a debelaram. Desse modo, observam-se lacunas que, caso superadas, poderiam permitir avançar em direção à governança integrada e sistêmica. Como metodologia utilizou-se a análise documental.

Além desta introdução e da conclusão, este artigo possui três seções. A primeira discute as mudanças do clima e o nexo WEF, considerando alguns elementos teóricos para a análise que se pretende e sistematiza a perspectiva da Comissão Econômica para a América Latina e o Caribe, CEPAL, para o tratamento da questão no âmbito regional. A segunda dispõe sobre as propostas brasileiras de adaptação às mudanças do clima, com foco para os desafios da segurança hídrica, energética e alimentar, conceitos tratados separadamente, mas articulados para efeito da análise. As políticas brasileiras são consideradas a partir das diretrizes do Plano Nacional de Adaptação às Mudanças Climáticas, PNAMC, para os setores Agricultura, Segurança Alimentar e Nutricional (SAN), Recursos Hídricos e Infraestrutura/Energia. A terceira seção traça um panorama da região nordeste do Brasil e das ações governamentais que visam garantir o acesso da população a água, energia e alimentos, sendo que a variável acesso inclui indicadores de distribuição e de estresse hídrico. 
Mudanças do clima e o nexo WEF

As MCs agravam pressões sobre os recursos naturais, notadamente os recursos de água potável, e ampliam a vulnerabilidade de pessoas e ecossistemas (ROCKSTRÖM et al., 2009). A produção e o fornecimento de energia e alimentos são alguns dos principais impulsionadores dessas mudanças, contribuindo para o aumento das emissões de Gases de Efeito Estufa (GEE). A água e os recursos necessários a agricultura são vulneráveis aos efeitos negativos das MCs, devido a secas prolongadas, desertificação, derretimento das geleiras, inundações etc. A expansão da produção de biocombustíveis pode ter forte impacto sobre o uso da água e do solo. Como praticamente metade das águas superficiais disponíveis são compartilhadas entre dois ou mais países, questões geopolíticas e aspectos relacionados a essa condição devem ser considerados (HOFF, 2011).

As MCs são a referência geral para se pensar a governança ambiental (GONÇALVES, 2011; VIOLA; FRANCHINI, 2012) a partir do nexo WEF (PEÑA, 2016). Os impactos negativos das MCs implicam consequências para os demais elementos que presidem as condições de vida na Terra (ROCKSTRÖM et al., 2009) com efeitos na produção de alimentos, na disponibilidade hídrica e em requisitos para a geração e distribuição de energia. Há demandas globais aos Estados para que, consideradas as suas vulnerabilidades, elaborem políticas de adaptação às MCs com diretrizes para os três setores em discussão, preferencialmente articuladas entre si. Organismos regionais têm desenvolvido políticas comuns para a adaptação às MCs. A CEPAL tem divulgado estudos sobre o nexo WEF em relação às MCs e às políticas de adaptação.

Neste artigo, o estudo e o desenvolvimento da abordagem a partir da perspectiva do nexo coloca a água como elemento chave porque é recurso insubstituível para diversas finalidades, de usos consuntivo e não consuntivo $^{5}$ (IRUJO, 2017). Como as MCs podem comprometer a disponibilidade dos recursos de água doce, ela é porta de entrada para a discussão proposta pela concepção do nexo WEF, conforme mostra a Figura 1.
5. Segundo a ANA, o uso consuntivo é todo tipo de uso que retira água do manancial (irrigação, abastecimento humano etc.); o não consuntivo não envolve o consumo direto da água (geração de energia hidrelétrica, lazer etc.). 
Figura 1 - Nexo entre água, energia e alimento

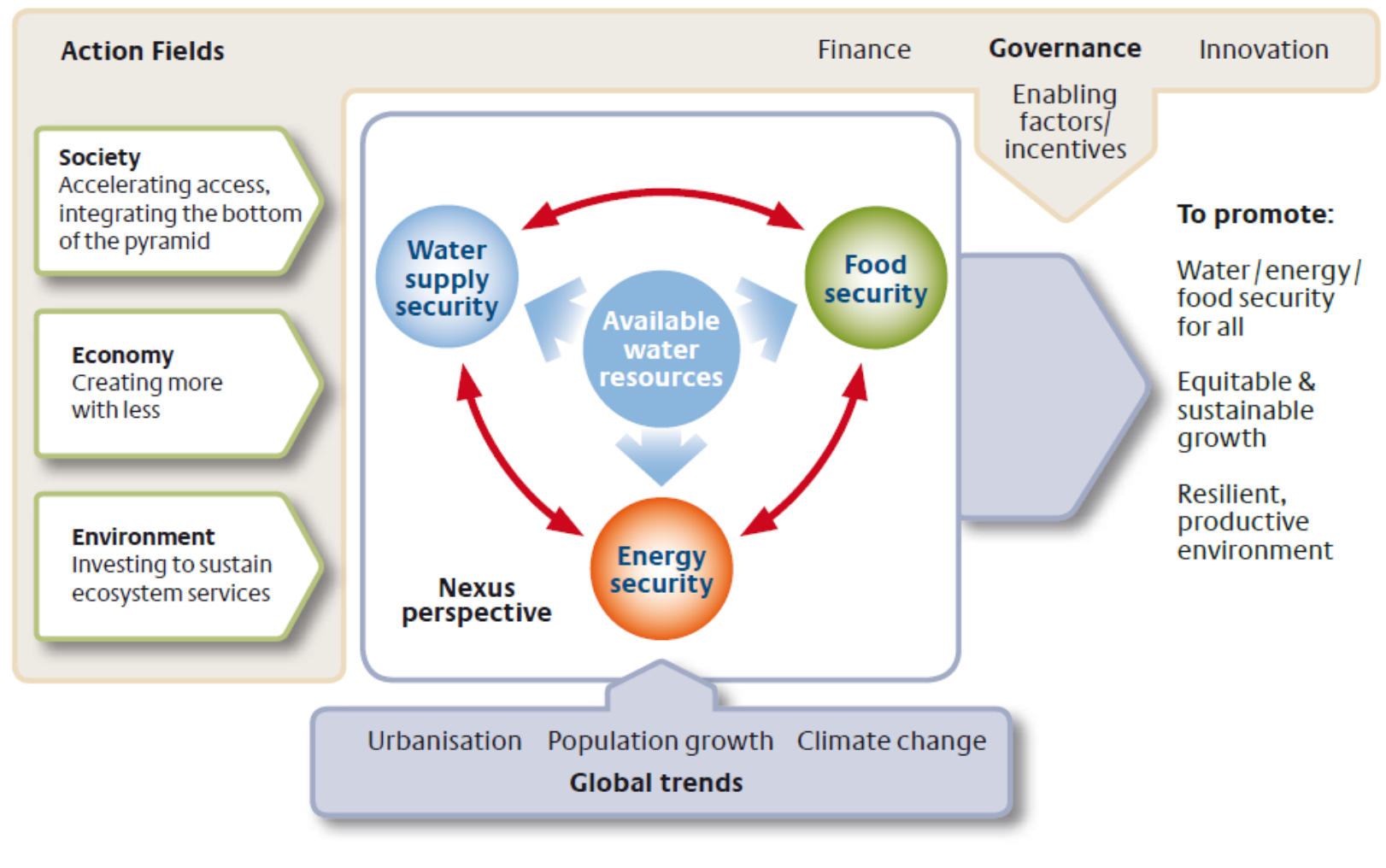

Fonte: HOFF, 2011, p. 16.

As MCs, urbanização e crescimento populacional formam o framework do nexo, tomando a disponibilidade hídrica como central aos três vetores: segurança hídrica, energética e alimentar. A sociedade, a economia e o meio ambiente são os campos de ação, dado que a perspectiva implica modelo de tomada de decisão. Devem-se ponderar fontes de recursos para o financiamento das políticas, formas de governança e desafios da inovação, estes voltados para atender necessidades de suprimento de água, energia e alimento, desafios do desenvolvimento equitativo e sustentável e demandas de resiliência do meio ambiente produtivo (HOFF, 2011).

Segurança hídrica consiste em garantir: disponibilidade de água adequada ao consumo humano, aos usos da subsistência, à proteção dos ecossistemas e à produção agropecuária e industrial; capacidade de acesso e uso sustentável da água e gerenciamento coerente com as inter-relações entre os diferentes setores de uso; nível aceitável de riscos associados à água, o meio ambiente e a economia (PEÑA, 2016). Segurança energética é garantir acesso suficiente e confiável aos combustíveis e serviços, incluindo disponibilidade dos recursos, redução da dependência de importações e da pressão sobre o meio ambiente, competição e eficiência do mercado, dependência dos recursos naturais ambientalmente não poluentes, e garantia de serviços de energia acessíveis, com distribuição equitativa (ÖLZ; SIMS; KIRCHNER, 2007; SOVACOOL, 2011). Segurança alimentar pode ser definida como a situação na qual "todas as pessoas tenham, sem interrupções, acesso físico e econômico a alimentos sufi- 
cientes, seguros e nutritivos para atender às suas necessidades e preferências alimentares para uma vida saudável” (FAO, 1996, s/p). Neste artigo, a conexão entre esses conceitos é feita a partir das MCs; a água é eixo estruturador, porque se entende que a sua governança e gestão devem ser integradas aos demais setores/recursos e porque a água é fundamental para a geração de energia e produção de alimentos.

A partir desses conceitos, o nexo WEF é também modelo de tomada de decisão e gestão de riscos (JOURAVLEVE, 2016), e pode ser considerado estratégia de governança, envolvendo a estruturação de políticas e mecanismos operativos (GONÇALVES, 2011). Segundo a CEPAL (2014), o cenário para a América Latina e Caribe (ALC) projeta continuidade no crescimento demográfico nas próximas décadas. A região vivenciou rápida e pouco planejada urbanização, com o surgimento e agravamento de vários problemas sociais (LOPEZ-GUNN, 2014), com cerca de $81 \%$ de sua população atualmente vivendo em áreas urbanas (WORLD BANK, 2018). Altos preços das commodities levaram alguns países a intensificar suas exportações, cerca de $70 \%$ delas relacionadas ao uso de recursos naturais. A Sociedade Nacional de Agricultura (2019, s/p) indica que "a região é responsável por $14 \%$ da produção e $23 \%$ das exportações mundiais agropecuárias e de pescados (...) chegando a $22 \%$ no caso dos cereais e a $16 \%$ nos produtos da pecuária”. Isso torna a região mais vulnerável a variações da economia global e das MCs. Apesar de reformas político-econômicas e maior abertura ao comércio internacional, o crescimento econômico da região nas últimas décadas não reduziu desigualdades sociais (CEPAL, 2014; 2019; LOPEZ-GUNN, 2014).

Na ALC, as MCs aumentam a vulnerabilidade ambiental, social e econômica. Dentre as preocupações para as próximas décadas quanto à disponibilidade de recursos hídricos destacam-se: mudanças no ciclo hidrológico; redução da disponibilidade hídrica, com aumento do consumo; perda de qualidade da água e riscos para a saúde humana; impactos nos ecossistemas e perda de biodiversidade; redução das áreas produtivas de alimentos e ameaças à segurança alimentar; diminuição da capacidade de geração de hidroeletricidade, com consumo de energia não renovável (CEPAL, 2020; LOPEZ-GUNN, 2014).

Estudos recentes confirmam a centralidade dos recursos hídricos sobre os temas ambientais e de desenvolvimento: segurança hídrica (GARRICK et al., 2020; PEÑA, 2016; UNESCO, 2012); água e segurança alimentar (FAO; WWC, 2015; LOPEZ-GUNN, 2014); governança dos recursos naturais (ALTAMONTE; SANCHEZ, 2016; FAO, 2011); desenvolvimento sustentável (CEPAL, 2015; 2016; FERRO, 2017); discussões do nexo WEF (BELLFIELD, 2015; EMBID; MARTIN, 2017; FAO, 2014; SIMPSON; JEWITT, 2019).

O nexo WEF na ALC pode ser descrito em interconexões prioritárias: água-energia; energia-água; água-alimentação; água-energiaalimentação, enfatizando principais características e desafios/riscos. Análises da CEPAL preconizam fortalecimento institucional e garantia dos direitos econômicos, sociais e culturais, entendendo-se que falhas de governança e instabilidade social são preocupações mais prementes e profundas do que a própria (in)disponibilidade dos recursos naturais, 
6. Segundo a International Energy Agency, a ALC apresenta os seguintes indicadores para geração de eletricidade por fonte (em GWh): carvão, 67423.0; óleo, 107142.0; gás natural, 249748.0; biocombustíveis, 71440.0; nuclear 21952.0; hídrica, 708302.0; geotérmica, 3895.0; eólica, 55809.0; outras fontes

447.0.

7. Essa dependência é de cerca de $65 \%$ na América Central e México; a água é muito utilizada nas regiões semidesérticas e desérticas de Argentina, Bolívia Brasil, Chile e Peru. catástrofes naturais e questões econômicas relativas aos preços (EMBID; MARTIN, 2017).

Água-Energia: a hidroeletricidade é central para a ALC por ser a principal fonte de energia, apresentando maior possibilidade de crescimento $^{6}$ (IEA, 2017). Dependência excessiva dessa fonte, tendo em vista efeitos das MCs sobre o ciclo hidrológico, pode ameaçar a segurança hídrica, energética e alimentar em alguns países. Exploração de hidrocarbonetos e mineração, cujas técnicas demandam quantidades significativas de água e energia, podem gerar impactos diretos. Essa interconexão é relevante para toda a região, embora não atinja igualmente a todos os países. Na ALC, à exceção das regiões áridas e semiáridas, o uso da água para a produção de energia é menor do que para a agricultura. Avalia-se que a irrigação gera conflitos em função dos deslocamentos populacionais e consequências associadas à qualidade da água. Salienta-se que a geração de hidroenergia não compromete a quantidade de água disponível, podendo contribuir para regular a vazão (EMBID; MARTIN, 2017).

Energia-Água: nessa relação, maior consumo energético está na captação, transporte e uso das águas subterrâneas, sobretudo para irrigação. Esse dispêndio aumenta com os subsídios para a extração de água dos aquíferos, ineficiência dos sistemas de irrigação e do equipamento de bombeamento. A crescente dependência das águas subterrâneas? impacta diretamente a disponibilidade do recurso, afetando seus diversos usos, notadamente a produção de alimentos, além dos custos energéticos para sua captação e tratamento (EMBID; MARTIN, 2017).

Água-Alimentação: Interconexão central para a sobrevivência humana, é fundamental para toda a ALC. A agricultura é atividade de uso consuntivo que mais demanda recursos hídricos, incluindo o consumo para produção de commodities, atividade muitas vezes associada ao desmatamento, perda de biodiversidade e deslocamento de população local, com consequências para a agricultura familiar ou de subsistência. Verifica-se aumento dos riscos de contaminação de solos e rios, erosão de terras e sedimentação do leito dos rios, com reflexos na quantidade e qualidade das águas (EMBID; MARTIN, 2017).

Água-Energia-Alimentação: Essa relação integra produção de biocombustíveis e modernização dos sistemas de irrigação. A produção de biocombustíveis consome água e energia e afeta diretamente a produção e os preços dos alimentos. Os biocombustíveis são relevantes para Argentina, Brasil e Paraguai e, em menor escala, para Peru, Colômbia e países da América Central. Essa interconexão sobre os sistemas de irrigação pode ser observada pela relação entre a energia gasta na captação e o desperdício no transporte da água para as atividades agropecuárias, assim como no nível de aproveitamento da água nessas atividades. Dada a relevância da agricultura, é urgente o aumento da eficiência dos usos da água. Tendo em vista as particularidades do nexo WEF destacadas, esse ponto é um dos principais gargalos para a promoção da segurança hídrica, energética e alimentar na ALC (EMBID; MARTIN, 2017).

A discussão desenvolvida no âmbito da CEPAL é insuficiente para se entender os desafios do nexo WEF na ALC. A diversidade de biomas, ecossistemas e as particularidades geográficas e político-sociais não per- 
mitem algumas generalizações. A Organização reconhece essas particularidades e destaca que os desafios da ALC seriam mais bem compreendidos em sub-regiões - Cone Sul; Região Andina; Região Amazônica, Mesoamérica e Caribe - e nacionalmente (EMBID; MARTIN, 2017).

\section{Brasil e os desafios do nexo WEF}

O Brasil tem avançado na superação de políticas tradicionais para o tratamento das interconexões entre alimento, água e energia. O Sistema Nacional de Gestão de Recursos Hídricos, órgão da Política Nacional de Recursos Hídricos, $\mathrm{PNRH}^{8}$, tem possibilitado sua descentralização através dos comitês de bacia hidrográfica (SOUZA, 2003), apesar de lacunas e dificuldades na sua implantação (MERCURE et al., 2019). A PNRH considera a água um bem de domínio público, cuja prioridade é o consumo humano e a dessedentação dos animais, e prevê a observância dos seus múltiplos usos. O Plano Nacional de Recursos Hídricos, PNRH, é um instrumento de gestão capaz de contemplar o nexo WEF, pois deve prever condições de disponibilidade hídrica para a produção de alimentos, geração de energia e outros usos (EMBID; MARTIN, 2017). Ele permite articular os demais recursos de gestão que integram os mecanismos operativos da política; deve estar em sintonia com o enquadramento das águas em classes de uso, contemplar o instrumento de outorga do uso da água, articulado à cobrança por tal uso, e prever a produção de informações para manter o Sistema Nacional de Informações sobre Recursos Hídricos, SNIRH (PUGA, 2018; SOUZA, 2003), além de outras funções.

O PNRH 2006-2020 indica caminhos para sua compatibilização com o planejamento de setores estratégicos: geração de energia, saneamento, navegação etc. Para atender ao nexo WEF, o planejamento dos recursos hídricos deve contemplar os setores de energia e alimentos (EMBID; MARTIN, 2017). Contudo, não é suficiente, sendo necessário envolver os planejamentos energético e de segurança alimentar (MERCURE et al., 2019). Para discutir os desafios relativos à observância do nexo WEF nas ações de governança ambiental identificaram-se as perspectivas e desafios do Brasil a partir do Plano Nacional de Adaptação às Mudanças Climáticas, PNA, que aponta vulnerabilidades e indica diretrizes para a gestão do risco e incremento da resiliência em vários setores.

Em linhas gerais, o PNA prevê, como impactos das MCs para o Brasil: extinção de habitat e de espécies, substituição de florestas tropicais por savanas e vegetação semiárida por árida; aumento de regiões em situação de estresse hídrico, dentre outros (ARAÚJO, OMETTO \& SOARES, 2019; MMA, 2016a). Ao delimitar seus princípios, o Plano ${ }^{9}$ adota governança vertical quanto às medidas de adaptação - federação, estados e municípios; e governança horizontal na formulação de respostas, que deverão contemplar a visão integrada das vulnerabilidades e garantir "interações e sinergias, respeitando as suas particularidades e dimensões institucional e social" (MMA, 2016a, p. 19). Contudo, a abordagem do PNA é setorial, reduzindo condições de aplicação do nexo WEF como modelo de tomada de decisão, dependendo das políticas estabelecidas, das possibilidades de sinergia entre suas estruturas de governança, principalmente aquelas em
8. A PNRH foi instituída pela Lei $N^{\circ}$ 9.433, de 08/01/1997.

9. 0 PNA foi instituído pela Portaria $\mathrm{N}^{0}$ 150, de 10/05/2016. Aborda: Agricultura, Recursos Hídricos, Segurança Alimentar e Nutricional, Biodiversidade, Cidades, Gestão de Risco de Desastres, Indústria e Mineração, Infraestrutura, Povos e Populações Vulneráveis, Saúde e Zonas Costeiras. 0 PNA existente é o de 2016, que possui um relatório de monitoramento, datado de 2017 
10. Os dados sobre SAN, no IBGE/ PNAD, são de 2013. Neles se observa que $76,7 \%$ da população urbana brasileira e $59,9 \%$ da população rura gozavam de segurança alimentar. IBGE.

Pesquisa Nacional por Amostra de Domicílios: Segurança Alimentar. Brasília, 2014 menor escala, nas quais a participação dos diversos atores sociais é mais visível. No Relatório de Monitoramento (MMA, 2017, p. 11), há registros de esforços para inserir diretrizes voltadas à adaptação às MCs nos planos nacionais de segurança hídrica e de segurança alimentar e nutricional.

Tendo isso em vista, apresenta-se síntese das diretrizes do PNA para agricultura, segurança alimentar e nutricional, SAN, recursos hídricos e infraestrutura de energia. Ela foi organizada a partir dos critérios de relevância, principais vulnerabilidades, demandas quanto à gestão do setor face às MCs e as diretrizes para as medidas de adaptação. Para cada um desses critérios observaram-se os setores indicados acima. A síntese foi elaborada a partir do PNA, Volumes 1 e 2 (MMA, 2016a; 2016b). Além dessa síntese, serão discutidos aspectos do planejamento para cada elemento do nexo WEF e pontuados aspectos conjunturais da temática.

Relevância: Em 2016, a agricultura brasileira era responsável por $23 \%$ do PIB e $35 \%$ dos empregos, com forte contribuição para a balança comercial, sendo o Brasil ator relevante na produção e exportação mundial de alimentos. A importância da SAN está no próprio fato de o país possuir uma política e um sistema específico, o SISAN, Sistema Nacional de Segurança Alimentar e Nutricional, conforme Lei No 11346/2006. Quanto aos recursos hídricos, o país possui $12 \%$ da água doce do planeta. E quanto à energia, a infraestrutura relacionada envolve a geração/produção, distribuição/transporte e consumo, cuja dinâmica se reflete em todos os setores econômicos e de apoio à vida. Com sua matriz energética fortemente ancorada na hidroeletricidade, o sistema de transmissão interconecta as diversas bacias hidrográficas, além da capacidade de geração adicional, integrada ao sistema quando há demanda provocada por escassez de água nos reservatórios.

Principais vulnerabilidades: O PNA identifica vulnerabilidades relacionadas ao efeito das MCs na agricultura, envolvendo variações de temperatura, radiação solar, chuva, umidade do ar e disponibilidade de água no solo com consequências diretas sobre a SAN e sobre os ecossistemas. Admitem-se impactos das condições meteorológicas nos insetos, polinizadores e predadores. Preveem-se alterações na distribuição das chuvas, com maior concentração de precipitações em um curto período, com reflexos na agricultura, uma vez que cerca de $20 \%$ da área cultivada é irrigada. Esses fatores resultam em perdas econômicas, redução da oferta de empregos e de alimentos e consequências para a SAN ${ }^{10}$ (IBGE, 2014).

No que respeita à SAN, as MCs afetam diretamente a produção de alimentos, com consequências para as populações pobres e para alguns grupos sociais específicos como extrativistas, indígenas, quilombolas, pescadores artesanais e agricultores ligados à agricultura familiar. As MCs reduzem a disponibilidade hídrica e acarretam eventos extremos como secas e inundações, com efeitos adversos na produção e produtividade agrícola que, repercussão na renda dos pequenos agricultores. $\mathrm{O}$ PNA (MMA, 2016a) estima, para 2030, redução de até 10,6 milhões de hectares de terras destinadas à agricultura, de áreas de florestas e matas nos estabelecimentos agrícolas, com aumento das áreas de pastagens; diminuição das áreas de baixo risco climático para plantio de lavouras, redistribuição regional de algumas culturas que migrariam em busca de 
condições climáticas mais adequadas, repercutindo no aumento das áreas destinadas à pecuária nas regiões rurais do Nordeste.

O PNA 2016 prevê aumento da criticidade hídrica para bacias hidrográficas da região Nordeste, com rápido declínio nos fluxos por volta do ano de 2100 , principalmente para as bacias da parte ocidental do Nordeste e do Atlântico Ocidental. Identifica tendência a declínio na oferta de água superficial para quase todas as regiões do Brasil, com possível impacto para a geração de energia, prevendo aumento na precipitação para a região Sul. A criticidade hídrica repercutirá nas águas subterrâneas: no Nordeste, redução na recarga dos aquíferos da ordem de $70 \%$ até 2050 ; no Sistema Aquífero Guarani, cerca de $2 / 3$ dos cenários climáticos projetam variações dos níveis freáticos abaixo dos medidos no monitoramento realizado entre 2004 e 2011. Além dos impactos esperados no regime hidrológico, projetam-se mudanças na demanda dos diversos setores usuários de águas com forte impacto no abastecimento humano; pressão da demanda reprimida para a universalização do serviço de abastecimento; conflitos entre usuários (MMA, 2016).

A infraestrutura para a geração de energia não pode ser analisada isoladamente em relação às bacias hidrográficas e aos recursos de água disponíveis. Desse modo, os impactos das MCs nos recursos hídricos, segundo o PNA 2016, terão efeito sobre as condições de geração de hidroeletricidade. Considerando que a elevação das temperaturas aumentará a demanda por energia, esforços serão requeridos para a inserção de novas tecnologias e substituição das fontes de geração de energia, como a eólica e a solar, dado que o aumento da biomassa para a produção de energia tem impactos diretos sobre a SAN, as condições hídricas e disponibilidade do solo.

Gestão do setor face às MCs - Considerando o nexo WEF, os mecanismos de gestão do setor deveriam seguir uma estrutura de governança sistêmica e coordenada, superando a setorialização e a fragmentação tanto das políticas quanto dos instrumentos de gestão disponíveis. Contudo, as recomendações constantes do documento no qual se baseia esta síntese foram elaboradas por setor. O importante é verificar se há observância do nexo.

No que respeita à agricultura, as recomendações do PNA são, em geral, fortalecimento de políticas públicas que ofereçam ao setor produtivo instrumentos que permitam ajustes de seus sistemas de produção, implicando revisão do Plano Setorial de Agricultura de Baixa Emissão de Carbono, das políticas públicas e dos instrumentos já existentes. Além disso, o PNA recomenda implantação efetiva das políticas existentes para o setor e revisão da legislação para construção de pequenas e médias barragens e aprimoramento dos procedimentos para a outorga do direito de uso da água. Recomenda, ainda, a construção de sistemas de captura e armazenamento de água para consumo humano e produção agrícola, principalmente no semiárido; introdução de variedades agrícolas de curto ciclo; criação de bancos comunitários de sementes; adaptação das práticas agrícolas para a conservação da umidade do solo; conservação e recuperação da agrobiodiversidade; fortalecimento das políticas de inclusão produtiva rural e da Política Nacional de Gestão Territorial e Ambiental de Terras Indígenas. 
No PNA, essas medidas estão relacionadas às de SAN, que recomendam implantar os instrumentos de gestão dos recursos hídricos. Assim, o Plano de Recursos Hídricos deve apontar os impactos das MCs sobre a disponibilidade hídrica e as demandas futuras, indicando diretrizes para a situação. Já o enquadramento dos corpos de água em classes de uso deve articular os planos municipais de saneamento, ampliar formas de financiamento, ampliar e padronizar o monitoramento da qualidade da água; recomenda adaptar o SNIRH, dotando-o de capacidade para fornecer dados atualizados e acessíveis aos interessados. Essas medidas estariam vinculadas à produção de energia hidroelétrica, que já possui um sistema integrado, o Operador Nacional do Sistema, ONS.

Essas recomendações expressam uma idealização do que deve ser. Sua efetivação é um desafio, principalmente quando se considera que as políticas são setoriais e os planos elaborados para a segurança hídrica e alimentar e o Plano Nacional de Energia são setoriais, elaborados por diferentes setores da burocracia, embora verifiquem-se esforços na articulação desses planos com áreas de interseção.

Diretrizes para a adaptação - O PNA (MMA 2016a; 2016b) expressa que, do ponto de vista do planejamento, o nexo WEF possivelmente orientou a elaboração de tais diretrizes. Pode-se identificar que os recursos hídricos são a mola-mestra do processo, como recurso fundamental para a agricultura. As principais recomendações para esse setor articulam a produção e conservação de água para o atendimento dos diversos usos, proteção de vegetação nativa e recomposição de áreas de proteção permanente; o uso da terra, zoneamento de risco e identificação de vulnerabilidades; além de busca por recursos financeiros, desenvolvimento e transferência de tecnologias, incentivo à pesquisa em temáticas relevantes; combate à desertificação; manejo de pragas e doenças; recursos genéticos e melhoramento; adaptação de sistemas de produção para sua sustentabilidade econômica, social e ambiental.

Em vista das diretrizes para a agricultura, muitos aspectos da SAN já estariam contemplados, mas ainda seriam relevantes: promoção de sistemas integrados de lavoura, pecuária e floresta; ampliação da capacidade de armazenamento da produção, associada a maior atuação do poder público como agente regulador de estoques públicos; melhoria do planejamento agrícola, com ampliação de estratégias para a sustentabilidade na produção de alimentos.

Intensificam-se recomendações voltadas para os recursos de água doce, relativas à proteção de quantidade e qualidade e à criação de mecanismos para solução de conflitos; estabelecimento de regras claras de utilização dos recursos hídricos, sanções compatíveis e melhoria da infraestrutura física, tecnológica e institucional para lidar com novos problemas no contexto das MCs. A necessidade de aliar a gestão das águas aos demais setores é mais clara nas orientações para o aumento da coerência e da consistência entre as políticas de águas e os setores relacionados, para garantir que os recursos hídricos sejam considerados na elaboração de planos e políticas públicas desses setores, além de aumentar a efetividade da governança das águas através das bacias hidrográficas. 
Quanto à energia, a principal diretriz é o maior envolvimento do setor elétrico aos desafios da adaptação, tendo em vista ajustar as políticas do setor ao contexto das MCs. Isso implica aprofundar estudos dos impactos das MCs no setor, dos riscos à infraestrutura face a esses mesmos impactos e avaliar interseções das medidas adaptativas entre água, energia, uso da terra e biodiversidade.

Efeitos para a região Nordeste, lacunas e consequências para o nexo WEF

A aplicação do nexo WEF para análise de políticas públicas é recente e relativamente limitada, principalmente porque, em geral, no caso do Brasil tais políticas ainda se ancoram em uma abordagem setorial, estabelecida pela própria estrutura institucional do país, ainda que em algumas políticas estejam previstos mecanismos de coordenação e gestão integrada. Recentes estudos destacam avanços nas abordagens do nexo WEF, porém enfatizam a dificuldade do governo brasileiro em adotar políticas públicas que contemplem de forma abrangente o nexo no contexto das MCs, seja por questões de falta de coerência entre as estruturas político-normativas dos setores (CARVALHO; SPARATU, 2018), pela diversidade de instâncias e atores envolvidos (PAIM et al., 2020), pela falta de capacidade da gestão pública em traduzir o quadro conceitual do nexo em políticas públicas adequadas (MILHORANCE; BURSZTYN, 2019), sobretudo no âmbito da gestão local (ARAÚJO et al., 2019). Em comum, todas essas perspectivas apontam para os entraves oriundos da governança pública setorial.

A Agência Nacional de Águas, ANA, tem envidado esforços no estudo da região do semiárido, que abrange grande parte do interior da região nordeste do Brasil, incluindo o norte de Minas Gerais (ANA, 2006). Esses esforços visam municiar gestores públicos de informações para atuação na região. Historicamente, o semiárido é a região que concentra os maiores problemas de escassez de água para abastecimento urbano e produção agropecuária (ANA, 2006; 2009; 2013; 2017). Em suas conclusões, o Atlas Nordeste (2006) avaliava que a situação hídrica de $70 \%$ dos municípios do semiárido era crítica, por falta de manancial suficiente para o abastecimento, pela qualidade da água ou pela precariedade do sistema de abastecimento.

Estudos recentes apontam que a região do semiárido nordestino é muito sensível às MCs, com maior propensão à ocorrência de eventos extremos, como ondas de calor e secas severas. Previsões para a região ressaltam forte probabilidade de diminuição de recursos hídricos superficiais e subterrâneos, com perda da biodiversidade da caatinga e avanço da desertificação (ARAÚJO, OMETTO \& SOARES, 2019; MILHORANCE; SABOURIN; CHECHI, 2018; MMA; MI; WWF, 2017). O panorama geral para o semiárido, portanto, é de piora dos indicadores socioeconômicos e de desenvolvimento. As condições socioeconômicas do sertão nordestino são consideradas entraves maiores do que o estresse hídrico. Nesse contexto, amplas medidas para garantir segurança hídrica, saneamento básico e educação são avaliadas como igualmente importantes na promoção do desenvolvimento (MMA, MI; WWF, 2017). 
11. A Companhia de Desenvolvimento dos Vales do São Francisco e do Parnaíba foi criada pelo governo federal, com outro nome, em 1948. Desde então, a Companhia tornou-se o principal órgão executor das atividades relativas aos recursos hídricos dessa bacia, executando diversos projetos e convênios em parcerias com estados e municípios. https://www.codevasf.gov.br/.

12. Informações sobre o PISF e outros projetos de segurança hídrica do Ministério do Desenvolvimento Regional: https://www.mdr.gov.br/seguranca-hi-

13. Informações sobre os relatórios do PISF realizados pelo Tribunal de Contas da União: https://pesquisa. apps.tcu.gov.br/\#/resultado/acordao-completo/PISF/\%2520/\%2520?ts $=1594054831299 \& \mathrm{pb}=$ acordao-com-
A bacia do São Francisco é a mais relevante de todo o semiárido, atravessando seis estados e banhando mais de 500 municípios da região, desde suas nascentes, em Minas Gerais até sua foz, em Alagoas (ANA, 2015). Junto com as atividades voltadas para a produção do Atlas Nordeste, a ANA também coordenou esforços para o desenvolvimento do Plano de Gerenciamento da Bacia do Rio São Francisco, que envolveu a atuação de vários órgãos e níveis de governo, sobretudo a CODEVASF"1, e contou com o apoio de organismos internacionais: o Fundo para o Meio Ambiente Mundial (GEF); o Programa das Nações Unidas para o Meio Ambiente (PNUMA), e a Organização dos Estados Americanos (OEA) (ANA, 2004).

O plano aprovado para o rio São Francisco contemplava atividades a serem realizadas entre 2004 e 2013 e visava fortalecer a capacidade de abastecimento urbano, o saneamento ambiental, a irrigação de culturas e a atividade pecuária. Desde os anos 1960 que a bacia recebe investimentos para a produção de energia hidrelétrica, contando com dezenas de usinas de variados portes, destacando-se Três Marias, Sobradinho, o complexo Paulo Afonso e Xingó (ANA, 2015). A bacia também recebeu importantes aportes ao longo das décadas para apoiar atividades agropecuárias, inclusive para a implantação de áreas públicas de irrigação por pivôs, com o intuito de criar polos de desenvolvimento (ANA, 2015). Nesse sentido, o foco do projeto era a melhoria daqueles usos da água que receberam pouca atenção ao longo do tempo, porém projetava-se que $77 \%$ da água retirada da bacia no período de vigência do projeto seriam para irrigação (ANA, 2004).

Além desses esforços, ressalta-se o Projeto de Integração do rio São Francisco (PISF). Esse rio, além de fornecer a água necessária à produção agropecuária do semiárido e ser a base da produção de energia hidroelétrica de todo o Nordeste, passaria a ter trechos transpostos, de modo a suprir a demanda por água da região abrangida também pela bacia do Atlântico Nordeste Oriental, caracterizada pela escassez de chuvas, longos períodos de estiagem, presença de rios intermitentes e por um imenso contingente populacional (ANA, 2015).

O PISF foi concebido a partir do nexo WEF. As fontes de águas integradas à bacia Nordeste Oriental advêm dos reservatórios formados pelas barragens das usinas hidrelétricas. Além disso, o volume de água e as distâncias a serem percorridas são tão relevantes que subestações de energias foram concebidas ao longo do trajeto para permitir o bombeamento da água. Ademais, ainda que a prioridade do projeto seja garantir o abastecimento urbano, espera-se expandir a área irrigada na região ${ }^{12}$.

A transposição do rio São Francisco, cujas obras permanecem, não tem ocorrido sem controvérsias e críticas sobre a relação custo-benefício do projeto. Dentre as considerações estão que os altos custos financeiros e ambientais da obra, não totalmente estimados pelo governo (CASTRO, 2011b), assim como o volume de água transposto e seu respectivo custo não seriam suficientes para a expansão qualificada da área irrigada (CASTRO, 2011a). Relatórios do Tribunal de Contas da União ${ }^{13}$ dão conta da evolução das obras ao longo dos anos e apontam casos de irregularidades, problemas de concepção de projeto, episódios de corrupção e pouca atividade de órgãos estaduais e municipais, responsáveis por contrapartidas do PISF, sobretudo quanto a obras de saneamento básico. 
Relatórios de conjuntura produzidos pela ANA (2009-2019) listam ações, projetos e programas, sobretudo a construção de açudes e adutoras de longa extensão, a fim de estabelecer a segurança hídrica no semiárido ao longo das últimas duas décadas. Eles são os principais documentos oficiais sobre os recursos hídricos brasileiros e abrangem: aspectos físicos do ciclo hidrológico; questões socioeconômicas dos usos consuntivos e não consuntivos da água; relação entre demandas e disponibilidade hídrica; organização legal e institucional da gestão dos recursos hídricos; e outorga do direito de uso da água. Esses relatórios, sobretudo os publicados em 2009, 2013 e 2017, que são relatórios base, permitem perceber o amadurecimento das discussões do nexo WEF e das mudanças do clima no Brasil. Neles as relações água-energia e água-alimentação e eventos extremos são abordados, com variado nível de informações.

No relatório de 2009, o nexo água-energia aparece apenas pela relevância da hidroenergia para a matriz energética do país. O documento mais recente relaciona o uso da água aos diversos setores da produção industrial. Ademais, as barragens das usinas hidrelétricas são entendidas e catalogadas como reservatórios de recursos hídricos. Para o nexo água-alimentação sempre houve mais informações. Se no relatório de 2009, a maior parte das informações era sobre o volume captado para a irrigação em geral, o relatório de 2017 contempla diferentes tipos de irrigação, diferentes níveis de captação e de retorno da água por tipo de cultura ou produção animal. Percebe-se, portanto, refinamento crescente na capacidade de coleta e sistematização das informações sobre os recursos hídricos no país, condição essencial para que as políticas públicas possam contemplar os desafios do nexo WEF. Por outro lado, esses documentos são silentes para o custo energético do bombeamento de água para os seus diversos usos, como também para o nível de contaminação das águas em função do uso de substâncias químicas na produção agropecuária.

Com relação aos eventos extremos no Brasil, sobretudo inundações e secas intensas, percebe-se a evolução das informações contidas nesses relatórios. Enquanto a publicação de 2009 é breve em suas considerações, a publicação de 2017 dedicou uma seção inteira para a temática. O documento apresenta dados quantitativos e o impacto dos eventos extremos para as atividades econômicas, bem como para o abastecimento dos grandes centros urbanos. Essa seção também mostra a evolução das discussões sobre segurança hídrica, base do Plano Nacional de Segurança Hídrica (PNSH), de 2019. Ressalta-se a relevância do Nordeste, sobretudo a região do semiárido, como mais vulnerável à escassez hídrica em todos os relatórios de conjuntura.

A partir desses documentos, identifica-se o importante papel desempenhado pela ANA para a compreensão do nexo WEF centralizado nos recursos hídricos, em um contexto de aumento de eventos críticos, seja pelas consequências das mudanças do clima ou pelo aumento da demanda por água. Além disso, no PNSH verificam-se esforços para maior conhecimento e produção de informações sobre a escassez de água, com impacto na segurança hídrica, na geração de energia e na produção de alimentos (ANA, 2019), e nele são consideradas as dimensões humana, econômica e ecossistêmica da segurança hídrica, além da capacidade de 
resposta a situações de maior escassez. Contudo, e apesar dos diversos esforços da ANA, o PNSH ainda trata superficialmente as MCs, e muito pontualmente o nexo água-energia.

De toda maneira, o planejamento é condição fundamental para o sucesso das políticas para a governança a partir do nexo WEF. Para tal, os Estados são instados a produzir informações detalhadas sobre as diferentes relações do nexo em âmbito local, de modo a elevar a capacidade de projeção de cenários adequados de médio e longo prazos; a estabelecer vínculos intersetoriais entre as áreas responsáveis pela gestão, tendo em vista a promoção da coordenação política e a otimização dos recursos investidos e aumentar o nível de participação social dos grupos interessados no planejamento e na implementação das ações, com o objetivo de estabelecer políticas mais adequadas e justas (EMBID; MARTIN, 2017).

Conclusão

Considerando a Figura 1, tendo em mente a síntese do PNA para cada setor envolvido, e sendo os recursos de água doce o eixo central e as mudanças climáticas o quadro de referência geral, conclui-se:

1. Quanto aos campos de ação:

a) Todos os setores tratam da sua relevância para o desenvolvimento, considerando as necessidades da população; os recursos de água doce, embora abundantes, devem estar ao alcance da população; a agricultura é fundamental para a geração de emprego e renda e a política de segurança alimentar e nutricional volta-se para o atendimento dos economicamente mais vulneráveis da população brasileira.

b) As medidas previstas no PNA, no que diz respeito à gestão dos setores face aos impactos das MCs, sugerem a necessidade de remodelar sistemas de gestão, repensar políticas, melhorar o uso dos recursos naturais, prevenir e evitar sua degradação.

c) Todos os setores discutem e indicam alternativas para a melhoria dos serviços ecossistêmicos e elas são mais evidentes para os setores de recursos hídricos e agricultura, provavelmente por sua maior vulnerabilidade e dependência de tais serviços.

2. Quanto ao financiamento: o PNA indica fontes de financiamento e informa que os recursos serão provenientes dos diversos órgãos envolvidos com as temáticas setoriais, cujos recursos são oriundos do planejamento público e fundos especialmente constituídos; outros instrumentos fiscais, orçamentários e fundos devem ser buscados. O PNA também aponta para a necessidade de fontes externas de financiamento como o GEF.

3. Quanto à governança: percebe-se que o setor que expressa visão integrada é o de recursos hídricos, ao sugerir um conjunto de medidas e ajustes na PNRH, nos seus instrumentos de gestão, além de propor maior integração entre as estruturas de gestão consideradas em suas interconexões. O setor de agricultura apresenta algumas propostas dentro de uma visão um pouco mais integrada. A perspectiva da segurança alimentar e nutricional, embora toque em aspectos da agricultura e dos recursos de água, não sugere alternativas para maior integração. O setor de energia, recomenda a observância de maior consenso entre suas estruturas buro- 
cráticas e sugere ponderar as interconexões entre energia, uso da terra e biodiversidade. Considera-se, neste caso, que a alusão ao uso da terra se relacione ao setor agrícola, mas, não necessariamente à produção de alimentos, dado que a produção de biomassa é fundamental para a manutenção de matriz energética limpa.

4. Quanto à inovação, o principal desafio seria a inovação institucional e o PNA não parece apontar nessa direção.

Analisando a estrutura central proposta pela perspectiva do nexo WEF, e a partir da sistematização das políticas previstas no PNA, entende-se que, muito embora a PNRH possa ser adaptada, em razão de ter sua concepção fundamentada em uma visão integrada, as políticas ambientais brasileiras foram formuladas setorialmente e suas estruturas de gestão se desenvolveram nessa perspectiva. Ademais, muito embora este artigo não tenha analisado o aparato organizacional criado para a gestão ambiental no Brasil, pode-se afirmar que ele é gigantesco e extremamente complexo. Além disso, ele se estrutura a partir de uma visão setorial. Desse modo, pode-se inferir muitos limites e dificuldades para se tratar a questão ambiental a partir dos nexos WEF. Sem alterações mais substantivas na concepção das políticas ambientais, considera-se que adotar a perspectiva do nexo geraria enormes problemas de coordenação entre os três setores, numa visão macro, e entre as estruturas burocráticas de cada um deles em seus diversos níveis - federal, estadual e municipal.

Pode-se admitir que, em alguns casos, tais mecanismos existem - seriam basicamente os conselhos previstos em algumas políticas, cuja composição permitiria incluir diversos setores, o que poderia promover maior integração. Ainda assim, faltam estudos mais robustos sobre o seu funcionamento, principalmente para se identificar problemas de coordenação, conflitos entre burocracias e entre interesses diversos, além de uma avaliação quanto ao acesso de stakeholders e possíveis desequilíbrios de poder entre os diversos setores que os constituem.

Desse modo, embora a CEPAL possa ver no Brasil um bom exemplo para se alcançar a governança ambiental a partir do nexo WEF, tal possibilidade ainda demanda grandes esforços no sentido de produzir mudanças mais substantivas na concepção da política ambiental e promover ampla reforma dos diversos mecanismos operativos existentes e que deveriam se adequar a essa nova concepção.

Referências

ALTAMONTE, Hugo; SÁNCHEZ, Ricardo. Hacia una nueva gobernanza de los recursos naturales en América Latina y el Caribe (LC/G.2679-P). Nações Unidas, Comisión Económica para América Latina y el Caribe (CEPAL), Santiago, 2016.

ANA. AGÊNCIA NACIONAL DE ÁGUAS (Brasil). Conjuntura dos recursos hídricos no Brasil 2009 - Relatório Pleno. Brasília, 2009. Disponível em: http://www.snirh.gov.br/portal/snirh/ centrais-de-conteudos/conjuntura-dos-recursos-hidricos. Acesso em: 02 jun. 2020

ANA. AGÊNCIA NACIONAL DE ÁGUAS (Brasil). Conjuntura dos recursos hídricos no Brasil 2013 - Relatório Pleno. Brasília, 2013. Disponível em: http://www.snirh.gov.br/portal/snirh/ centrais-de-conteudos/conjuntura-dos-recursos-hidricos. Acesso em: 02 jun. 2020.

ANA. AGÊNCIA NACIONAL DE ÁGUAS (Brasil). Conjuntura dos recursos hídricos no Brasil 2017 - Relatório Pleno. Brasília, 2017. Disponível em: http://www.snirh.gov.br/portal/snirh/ centrais-de-conteudos/conjuntura-dos-recursos-hidricos. Acesso em: 02 jun. 2020. 
ANA. AGÊNCIA NACIONAL DE ÁGUAS (Brasil). Conjuntura dos recursos hídricos no Brasil: regiões hidrográficas brasileiras - Edição Especial. Brasília, 2015. Disponível em: http:// www.snirh.gov.br/portal/snirh/centrais-de-conteudos/conjuntura-dos-recursos-hidricos. Acesso em: 02 jun. 2020.

ANA. AGÊNCIA NACIONAL DE ÁGUAS (Brasil). Plano de Recursos Hídricos da Bacia do Rio São Francisco. Brasília, 2004. Disponível em: http://www.saofrancisco.cbh.gov.br/_docs/ planos/PlanoDecenaldeRecursosHidricos.pdf Acesso em: 02 jun. 2020.

ANA. AGÊNCIA NACIONAL DE ÁGUAS. (Brasil). Atlas Nordeste: abastecimento urbano de água - alternativas de oferta de água para as sedes municipais do Nordeste do Brasil e do norte de Minas Gerais. Brasília, 2006. Disponível em: http://arquivos.ana.gov.br/institucional/sge/ CEDOC/Catalogo/2006/AtlasNordesteENorteMinasLivro.pdf. Acesso em: 03 jun. 2020.

ANA. Agência Nacional de Águas. Plano Nacional de Segurança Hídrica. Brasília. 2019. Disponível em: http://arquivos.ana.gov.br/pnsh/pnsh.pdf. Acesso em: 03 jun. 2020.

ARAÚJO, Moacyr; OMETTO, Jean; SOARES, Ana Paula. Impactos das mudanças climáticas no Brasil e caminhos para a sustentabilidade. São José dos Campos, SP: Rede Clima, 2019. Disponível em: http://redeclima.ccst.inpe.br/papers/. Acesso em: 01 jun. 2020

ARAÚJO, Moacyr; OMETTO, Jean; RODRIGUES-FILHO, Saulo; BURSZTYN, Marcel; LINDOSO, Diego; LITRE, Gabriela; GAIVIZZO, Larisa; FERREIRA, Julia; REIS, Rafael; ASSAD, Eduardo. The socio-ecological Nexus approach used by the Brazilian Research Network on Global Climate Change. Current Opinion in Environmental Sustainability, v. 39, p. 62-70, 2019. Disponível em: https://www.sciencedirect.com/science/article/pii/S1877343518301337?via\%3Dihub. Acesso em: 29 mai. 2020

BELLFIELD, H. Water, Energy and Food Security Nexus in Latin America and the Caribbean: Trade-offs, Strategic Priorities and Entry Points. Global Canopy Programme, 2015. Disponível em https://iwa-network.org/wp-content/uploads/2017/03/The-Water-Energy-Food-Nexus-in-LAC-April-2015-lower-res.pdf. Acesso em: 04 mai. 2020.

BENJAMIN, Antônio Herman, IRIGARAY, Carlos Teodoro. J. H., LECEY, Eládio, CAPPELLI, Silvia. PNMA: 30 anos de política nacional de meio ambiente. São Paulo: Imprensa Oficial, 2011.

CARVALHO, Priscila; SPATARU, Catalina. Advancing the Implementation of SDGs in Brazil by Integrating Water-Energy Nexus and Legal Principles for Better. Sustainability in Environment, v. 3, n. 3, 2018. Disponível em: http://www.scholink.org/ojs/index.php/se/article/ view/1572/1718. Acesso em: 04 mai. 2020

CASTRO, César Nunes de. Impactos do projeto de transposição do rio São Francisco na agricultura irrigada do nordeste setentrional. Rio de Janeiro/RJ, 2011a. Disponível em: https:// www.ipea.gov.br/portal/images/stories/PDFs/TDs/td_1573a.pdf. Acesso em: 19 abr. 2020.

CASTRO, César Nunes de. Transposição do Rio São Francisco: análise de oportunidade do projeto. Rio de Janeiro/RJ: IPEA, 2011b. Disponível em: http://www.ipea.gov.br/portal/images/stories/PDFs/TDs/td_1577.pdf. Acesso em: 19 abr. 2020.

CEPAL. Comisión Económica para América Latina y el Caribe. Pactos para a igualdade: Rumo a um futuro sustentável (LC/G.2587). Santiago, 2014

CEPAL. Comisión Económica para América Latina y el Caribe. América Latina y el Caribe: una mirada al futuro desde los Objetivos de Desarrollo del Milenio. Informe regional de monitoreo de los Objetivos de Desarrollo del Milenio (ODM) en América Latina y el Caribe (LC/G.2646). Santiago, 2015.

CEPAL. Comisión Económica para América Latina y el Caribe. Horizontes 2030: a igualdade no centro do desenvolvimento sustentável (LC/G.2660/Rev.1). Santiago, 2016.

CEPAL. Comisión Económica para América Latina y el Caribe. Panorama Social de América Latina, 2019 (LC/PUB.2019/22-P/Re v.1), Santiago, 2019. Disponível em: https://repositorio.cepal.org/bitstream/handle/11362/44969/5/S1901133_es.pdf. Acesso em: 03 jul. 2020.

CEPAL. Comisión Económica para América Latina y el Caribe. Anuario Estadístico de América Latina y el Caribe, 2019 (LC/PUB.2020/2-P), Santiago, 2020. Disponível em https://www. cepal.org/es/publicaciones/ae. Acesso em: 03 jul. 2020.

CODEVASF. Companhia de Desenvolvimento dos Vales do São Francisco e do Parnaíba. https://www.codevasf.gov.br/. Acesso em 26 mai. 2020

EMBID, Antonio; MARTIN, Líber. El Nexo entre el agua, la energía y la alimentación en América Latina y el Caribe Planificación, marco normativo e identificación de interconexiones prioritárias. CEPAL: Santiago, 2017. 
FAO.The State Of Food And Agriculture. Roma, 1996. Disponível em: http://www.fao.org/ docrep/003/w1358e/w1358e00.htm. Acesso em: 13 set 2017.

FAO. The state of the world's land and water resources for food and agriculture (SOLAW) - Managing systems at risk. Food and Agriculture Organization of the United Nations, Rome, and Earthscan, London, 2011.

FAO. The Water-Energy-Food Nexus: a new approach in support of food security and sustainable agriculture. Food and Agriculture Organization of the United Nations (FAO), Rome, 2014.

FAO; WWC. Towards a Water and Food Security Future: Critical Perspectives for Policy-makers. Food and Agriculture Organization of the United Nations (FAO), Rome, and World Water Council (WWC), Marseille, 2015.

FERRO, Gustavo. América Latina y el Caribe hacia los Objetivos de Desarrollo Sostenible en agua y saneamento: Reformas recientes de las políticas sectoriales. Santiago: CEPAL, 2017.

Garrick, D. Iseman, T. Gilson, G. Brozovic, N., O’Donnell, E., Mathews, N. Miralles-Wilhelm, F., Wight C., Young, W. Scalable solutions to freshwater scarcity: Advancing theories of change to incentivise sustainable water use. Water Security, v. 9, 2020. Disponível em: https://doi.org/10.1016/j.wasec.2019.100055. Acesso em: 04 mai. 2020

GONÇALVES, Alcindo Fernandes. Governança Global e Regimes Internacionais. São Paulo: Almedina, 2011.

HOFF, Holger. Understanding the Nexus. Background Paper for the Bonn 2011 Conference: The Water, Energy and Food Security Nexus. Stockholm: Stockholm Environment Institute, 2011. Disponível em: www.sei.org/publications/understanding-the-nexus. Acesso em: 30 mar. 2020.

IBGE, INSTITUTO BRASILEIRO DE GEOGRAFIA E ESTATÍSTICA. Pesquisa Nacional por Amostragem de Domicílio. Segurança Alimentar. Brasília: IBGE, 2014. Disponível em: https://biblioteca.ibge.gov.br/visualizacao/livros/liv91984.pdf. Acesso em 25 mai. 2020.

IEA, INTERNATIONAL ENERGY AGENCY. World Energy Outlook 2017. Disponível em: https://www.iea.org/reports/world-energy-outlook-2017. Acesso em 03 jul. 2020.

IRUJO, Antônio Embid. Propuestas para un mejor manejo de las interrelaciones entre el agua, la energia y la alimentación en America Latina e el Caribe. Presentacion Taller Nacional: "El Nexo entre el agua, la energía y la alimentación en la Cuenca del Río Reventazón". San Jose, Costa Rica, 7 de Junio de 2017. Disponível em: https://www.cepal.org/sites/default/files/ events/files/1.1_presentacion_del_sr._antonio_embid.pdf. Acesso em: 18 mai. 2020

IISD, INTERNATIONAL INSTITUTE FOR SUSTAINABLE DEVELOPMENT IISD). Sustainable Development Hub. Bonn 2011 Conference: The Water Energy and Food Security Nexus - Solutions for the Green Economy. Disponível em: sdg.iisd.org/events/bonn-2011-conference. Acesso em: 03 jul. 2020.

JOURAVLEVE, Andrei S. Introducción a la temática Nexo agua, energía y alimentación. Apresentação durante Reunión de Expertos "Gobernanza del Nexo Agua, Energía y Alimentación: Desafíos de la Agenda 2030 en Agua y Saneamiento". Antigua, Guatemala. Setembro de 2016.

LOPEZ-GUNN, Elena et al. Socio-economic megatrends for water and food security in Latin America. In: WILLAARTS, Bárbara; GARRIDO, Alberto \& LLAMAS, Ramón (Orgs.). Water for Food Security and Well-Being in Latin America and the Caribean: Social and Environmental Implications for a Globalized Economy. Nova Iorque: Ed. Routledge, 2014.

MERCURE, J. F; PAIM, M.A.; BOCQUILLON, P.; LINDNER, S.; SALAS, P.; MARTINELLI, P.; BERCHIN, I. I.; ANDRADE GUERRA, J. B. S. O. de; DERANI, C.; ALBUQUERQUE JUNIOR, C. L. de; RIBEIRO, J. M. P.; KNOBLOCH, F.; POLLITT, H.; EDWARDS, N. R.; HOLDEN, P. B.; FOLEY, A. SCHAPHOFF, S.; FARACO, R. A.; VINUALES, J. E. System complexity and policy integration challenges: The Brazilian Energy-Water-Food Nexus. In Renewable and Sustainable Energy Reviews, v. 105, p. 230-243, January, 2019. https://doi.org/10.1016/j.rser.2019.01.045. Acesso em: 05 mai. 2020

MILHORANCE, Carolina; BURSZTYN, Marcel. Climate adaptation and policy conflicts in the Brazilian Amazon: prospects for a Nexus + approach. Climatic Change, v. 155, n. 215-236, 2019.

MILHORANCE, Carolina; SABOURIN, Eric e CHECHI, Letícia. Adaptação às mudanças climáticas e integração de políticas públicas no semiárido pernambucano. Texto para Discussão Série Working Papers, n. 1, 2018, CDS/UnB e CIRAD. Disponível em: https:// agritrop.cirad.fr/594709/1/WP1\%20-\%20Adapta\%C3\%A7\%C3\%A30\%20\%C3\%A0s\%20mu- 
dan $\%$ C3\%A7as\%20clim\%C3\%A1ticas\%20e\%20integra\%C3\%A7\%C3\%A30\%20de\%20pol\%C3\%ADticas\%20p\%C3\%BAblicas\%20no\%20semi\%C3\%A1rido\%20pernambucano.pdf. Acesso em: 04 mai. 2020

MMA, MINISTÉRIO DO MEIO AMBIENTE (Brasil). Plano Nacional de Adaptação à Mudança do Clima: volume 1: estratégia geral. Brasília: MMA, 2016a

MMA, MINISTÉRIO DO MEIO AMBIENTE (Brasil). Plano Nacional de Adaptação à Mudança do Clima: volume 2: estratégias setoriais e temáticas. Brasília: MMA, 2016b.

MMA, MINISTÉRIO DO MEIO AMBIENTE (Brasil). Plano Nacional de Adaptação à Mudança do Clima: $1^{\circ}$ Relatório de Monitoramento, 2016-2017. Brasília, 2017.

MINISTÉRIO DO MEIO AMBIENTE (MMA), MINISTÉRIO DA INTEGRAÇÃO INTERNACIONAL (MI) (Brasil) e WWF-Brasil. Índice de vulnerabilidade aos desastres naturais relacionados às secas no contexto da mudança do clima. Brasília, DF: MMA, 2017. Disponível em: https://wwfbr.awsassets.panda.org/downloads/estudo_secas_completo_com_isbn.pdf. Acesso em: 05 mai. 2020.

ÖLZ, Samanta; SIMS, Ralph; KIRCHNER, Nicolai. Contributions of renewables to energy security: International Energy Agency. Energy technology perspective: Scenarios and strategies 2050. International Energy Agency, OECD/IEA, abril de 2007. Disponível em https://webstore.iea.org/download/direct/919. Acesso em: 05 jan. 2019.

PAIM, Maria-Augusta; SALAS, Pablo; LINDNER, Sören; POLLITT, Hector; MERCURE, Jean-Francois; EDWARDS, Neil R. \& VIÑUALES, Jorge E. Mainstreaming the Water-Energy-Food Nexus through nationally determined contributions (NDCs): the case of Brazil. In: Climate Policy, 20:2, 163-178, 2020. Disponível em: https://www.tandfonline.com/doi/full/10.1080/14 693062.2019.1696736

PEÑA, Humberto. Desafíos de la seguridad hídrica en América Latina y el Caribe. Nações Unidas, Comisión Económica para América Latina y el Caribe (CEPAL), Santiago, 2016. Disponível em: https://www.cepal.org/es/publicaciones/40074-desafios-la-seguridad-hidrica-america-latina-caribe. Acesso em: 30 mar. 2020.

PUGA, Bruno Pereguina. Governança dos recursos hídricos e eventos climáticos extremo.: a crise hídrica de São Paulo. 2018. Tese (Doutor em Desenvolvimento Econômico). Universidade Estadual de Campinas, Campinas, SP, 2018. Disponível em https://observatoriodasaguas. org/wp-ontent/uploads/sites/5/2018/11/Puga_BrunoPeregrina_D.pdf. Acesso em: 02 jul. 2020.

ROCKSTRÖM, Johan et al. Planetary Boundaries: Exploring the Safe Operating Space for Humanity. Ecology and Society, v. 14, n. 2/art 32. Disponível em: https://www.ecologyandsociety. org/vol14/iss2/art32/. Acesso em: 05 jan. 2019.

SIMPSON, Gareth B., JEWITT, Graham P. W. The Development of the Water-Energy-Food Nexus as a Framework for Achieving Resource Security: A Review. Frontiers in Environmental Science, v. 7, 2019. Disponível em: doi.org/10.3389/fenvs.2019.00008. Acesso em: 03 jul. 2020.

SNA, SOCIEDADE NACIONAL DE AGRICULTURA. América Latina mostra força na exportação agropecuária. 09 jul. 2019. Disponível em: https://www.sna.agr.br/america-latina-mostra-forca-na-exportacao-agropecuaria/. Acesso em: 03 jul. 2020.

SOUZA, Matilde de. Solidariedade e interesses na gestão de recursos hídricos. 2003. (Doutorado em Ciências Humanas: Sociologia e Política) - Universidade Federal de Minas Gerais, Belo Horizonte, fevereiro de 2003. Disponível em: https://repositorio.ufmg.br/bitstream/1843/ VCSA-6W9HQF/1/tesematilde.pdf. Acesso em 05 jan. 2019.

SOVACOOL, Benjamin K. Defyning, measuring, and exploring energy security. In: SOVACOOL, B. K. The Routledge handbook of energy security. Abingdon: Routlegde, 2011. p. 1-42

UNESCO. Water Security: Responses to local, regional, and global challenges. International Hydrological Programme (IHP). United Nations Educational, Scientific and Cultural Organization (UNESCO), Paris, 2012.

WORLD BANK. World Urbanization Prospects: 2018 Revision. Disponível em https://data. worldbank.org/indicator. Acesso em: 03 jul. 2020.

VIOLA, Eduardo; FRANCHINI, Mathias. Sistema Internacional de hegemonia conservadora: o fracasso da Rio + 20 na governança dos limites planetários. Ambiente e Sociedade, São Paulo, v. 15, n. 3, dez. 2012. 